\title{
Architectural heritage knowledge modelling: An ontology-based framework for conservation process
}

\author{
Marta Acierno $^{\mathrm{a}, *}$, Stefano Cursi ${ }^{\mathrm{b}, 1}$, Davide Simeone ${ }^{\mathrm{b}, 1}$, Donatella Fiorani ${ }^{\mathrm{a}, 2}$ \\ a Department of History, Representation and Restoration of Architecture, Sapienza University of Rome, Piazza Borghese, 9, 00186 Rome, Italy \\ ${ }^{\mathrm{b}}$ Department of Civil, Construction and Environmental Engineering, Sapienza University of Rome, Via Eudossiana, 18, 00184 Rome, Italy
}

\section{A R T I C L E I N F O}

\section{Article history:}

Received 14 April 2016

Accepted 29 September 2016

Available online 1 November 2016

\section{Keywords:}

Architectural heritage

Ontologies

Knowledge modelling

Investigation and conservation process

Building information modelling

\begin{abstract}
A B S T R A C T
This paper presents an ontology-based model to support the representation and management of information and knowledge during investigation activities for the conservation of architectural heritage. Despite the significant impact of information and communications technology (ICT) on architectural heritage, current approaches to its use in this context are often conceived only to provide flexible and reusable tools and methodologies, thus proposing oversimplified procedures that are ultimately insufficient for a truly accurate conservation project. A few experiences recently have focused much attention on the specifics of conservation. Although they have generally been concerned with the specific activities and knowledge domains related to conservation processes (such as cataloguing or monument damage), the importance of dealing with them in an integrated way is often neglected. Hence, each step of the process - such as the preliminary phase of knowledge acquisition, the summaries, which facilitate the assessment of value, diagnostics, design, the construction phase, and maintenance - is treated in isolation from all the other activities. This lack of synergy often compromises the final result. In order to deal with the complexity of representing historical architecture, and its conservation process, this proposed model defines four main knowledge domains (artefact - lifecycle - architectural heritage investigation process - actors), in which all the knowledge related to each artefact is formalized through semantic networks, in terms of entities, properties and relationships. Specific reasoning and inference rules allow checking of the model for coherence, in order to reduce information discrepancies, inconsistencies and errors. The proposed model offers a high level of accuracy in its capacity for description and, at the same time, a broad versatility within representation modelling, allowing such a reliable representation of multiple issues that eventually it may be required for every historical building, depending on its features and state of conservation. Moreover, the versatility of the model provides a suitable representation even for the different nature of the investigation activities results - whether analytical or hermeneutical. Finally, the knowledgebase has been connected with a building information modelling environment, providing an effective integration between geometrical and non-geometrical information.
\end{abstract}

(C) 2016 Elsevier Masson SAS. All rights reserved.

\section{Research aims}

This piece of research aims to conceptualise and develop a knowledge-based model for the representation of architectural heritage, in order to support both the investigation and design phases of the conservation process. The aim of the investigation

\footnotetext{
* Corresponding author. Tel.: +390635453388.

E-mail addresses: acierno.marta@gmail.com, marta.acierno@uniroma1.it (M. Acierno), stefano.cursi@uniroma1.it (S. Cursi), davide.simeone@uniroma1.it (D. Simeone), donatella.fiorani@uniroma1.it (D. Fiorani).

1 Tel.: +39 0644585384 .

2 Tel.: +390649918811
}

phase is to define a representation of knowledge that suits the richness and specificity of information relating to historical architecture. The design phase has the goal of creating a model that is able to provide and manage investigation results that can be used for conservation planning, and to act as a support for design decision-making. The proposed model has at its core a knowledge base developed through information ontologies and oriented around the formalization and computability of all knowledge necessary for the full comprehension of the object of architectural heritage.

Rather than forcing modelling approaches from other fields into built heritage practice, the research presented in this paper focuses on the development of an approach towards the representation of ad-hoc knowledge, methodology, and tools, in order to fit the 
requirements of historical architecture conservation, according to its specificity and unique qualities.

\section{Introduction}

All endeavours towards representing and managing knowledge within the field of architectural heritage conservation should necessarily consider complexity and specificity of conservation activities. Every heritage intervention is developed on the knowledge of the fabric of the building and, to achieve full comprehension, the investigation process is articulated around two processes: an examination of the building, and its critical appraisal. The first relies on a specialized and mainly analytic approach (developed by multiple professionals such as historians, physicists, chemists and biologists), while the second is built on interpretative and critical activities (performed by a conservation architect). These activities, gathering all the information provided by the investigation process, lead to an assessment that gives purpose and direction to the conservation design. This synthesis should consider each individual clue, avoid inner contradictions and merge materials and shapes, history and function, buildings and meaning in a coherent and organic framework.

While information and communication technology (ICT) have proved their efficacy in controlling particular aspects of representing historical architecture (such as the accuracy of 3D representation of artefacts, or the ability to digitally archive documentation), some limits and criticisms have arisen in terms of their actual suitability to architectural heritage conservation projects. One initial limit is the excessive standardization of current ICT-aided modelling approaches, and tools that clash with the uniqueness and unrepeatability of historical architecture; a second is related to interdisciplinary features of the investigation and conservation process, in which many different specialists operate together. Each uses their own set of models, methods, tools and jargon, and it is difficult to find an ICT framework that effectively supports such diverse information, knowledge sharing, and collaboration.

Looking at the complexity of information required to fully represent and comprehend an architectural heritage artefact, this research has assumed as a hypothesis that a model for knowledge representation and management, guided in its conception and development by heritage conservation professionals, may arise from the use of information ontologies. Ontologies in information technology have been developed to provide a computable knowledge base consisting of a primitive system of representation through which it is possible to model a domain of knowledge. The primitives for representation are 'classes', 'properties' and 'relationships'. Therefore, an ontology is a definition of concepts that belong to a particular knowledge domain which includes the meanings, description, and the relationships between them [1,2], thus a formalization of contents within a logical network that can be managed by all the experts who are involved.

Indeed ontologies may well be able to describe all the information gathered to realize the conservation project, and in the meantime corroborate how the knowledge represented is interpreted. The structure of the ontology, to be properly processed, needs to be worked on jointly by knowledge engineers and domain experts. The former, informatics experts especially skilled in ontology representation language [ontology web language $(\mathrm{OWL})$ ] write the programs and manage logical coherence. The domain experts, cultural heritage professionals, are all those who contribute to the knowledge necessary to allow the conservation of a historical building from the commencement of the conservation project, to its eventual use and maintenance. They have a duty of care about the structure, and they verify its representativeness and responsiveness of its contents.

Formalizing such knowledge requires a highly accurate procedure in the definition of the concepts' semantics, and particular attention paid to describing the logical structure in which the semantics have to be represented. The purpose of checking both the description of a single item and the relationships, physical and conceptual, that involve it, works towards a deeper and wider comprehension of the heritage domain. In addition, such a dynamic approach is able to cope with the abiding dialectic between analysis and interpretation that typifies the approach to knowledge in a conservation project [3].

On this basis, the present model, apart from concerning the figurative, constructive and material features of a building (provided by the architectural survey, decay survey, chemical, biological or physical investigations, etc.) also aims to incorporate the indirect knowledge made up of the heterogeneous and critical assumptions provided by studies that are carried out within a conservation project [4].

\section{Current state of the art}

In architectural heritage, one of the main results of the pervasive use of ICT technologies, in addition to the creation of applications of this kind, has been the generation of a large amount of digital data, often produced by different actors through completely noninteroperable methods and systems. At present, the main feature of this data is the vast heterogeneity relating to the types of media and transmission formats, the accessibility level, the logical and structural models used for their definition, and the consistency of the information represented [5].

As mentioned above, one of the most recent solutions for creating a formal, shared and explicit description of information, even in the field of cultural heritage, is the use of special schemes called ontologies. In a cultural heritage context, the main ontological reference model that can be classified as core ontology is the CIDOC Conceptual Reference Model (CIDOC CRM) [6]. This ontology became the ISO standard in 2006 and to date allows the formal and highly specific representation of information about cultural heritage, together with a representation of the concepts of space and time, thus supporting operations of reasoning and inference.

While the CIDOC CRM model was developed mainly to manage the cataloguing of cultural heritage documentation, other domainspecific ontologies have been progressively introduced to represent other aspects of the heritage conservation process. As an example, Cacciotti et al. [7] proposed the Monument Damage Information System (MONDIS) that focuses on an ontological framework that can coordinate a systematic approach to the documentation of damaged historical structures, their diagnosis, and possible interventions.

While the literature on ontologies for cultural heritage is sufficiently wide, few attempts have been made to apply ontologybased modelling approaches to architectural heritage. Agathos and Kapidakis [8] used the CIDOC CRM template to derive the Architecture Metadata Object Schema (ARMOS) for the cataloguing of architectural heritage, focusing in particular on the formal aspects of architectural design. In terms of the investigation process, Mecca et al. [9] proposed a very specific ontology for a diagnostics workflow regarding earthen architecture, in order to formalize various collections of information guidelines.

Recently, there have been experiments regarding the application of ICT approaches to cultural heritage, derived from the architecture, engineering and construction (AEC) fields - such as building information modelling (BIM) and industry foundation classes (IFC) - to overcome these limits [10-12]. Along these lines, 
ontologies have been used as a way to integrate semantics in the 3D representation of historical artefacts, in some cases filtered through IFC templates [13], while in others by connecting them directly to building information models [14].

These examples show the potential of applying ontology-based models to heritage representation, documentation, and analysis. Nevertheless, these experiments are still currently too domainspecific, so a more general knowledge-based model, one that in particular is able to formalize all the information related to an architectural heritage artefact in a homogenous way, is still missing.

\section{An ontological model for the representation of architectural heritage}

The formalization of an ontology starts from the definition of the contents and develops through the identification of semantic categories that can represent them. This corresponds to the definition of the classes that concern either principal or collateral concepts. The latter may be connected to the former through general relationships - such as inheritance or assembly - or through domain-specific ones.

This process, far from being a simple taxonomic description of the treated object, necessarily incites deeper focus on the object's broad context, leading to the definition of an appropriate conceptlogic network. This network is further enriched by the description of the entities and of the relationships that occur between them. The definition of a class includes all declarative aspects associated with the meaning of the represented entity, even in relation to the different domains of knowledge under consideration, thus implying that all the represented knowledge is directly related to the specific ontology [15]. According to OWL, properties may appear as data properties or object properties. Data properties include all descriptive and behavioural aspects that relate to the entities under consideration - such as their geometrical, physical and behavioural features - which are defined by specific values associated with those attributes. Instead, the object properties represent the connections that exist between each entity and the others, within and between the knowledge domains that are involved.

During the process of instantiation of an entity, the operator chooses from the ontology a class that he or she wants to employ and turns it into an instance, completing its object and data-property values.

The modelling of each instance is closely related to the representation of the various conceptual structures that are connected with it, and to the definition of the entire network to which it pertains. In this way, it is possible to provide a model which seeks fully to represent the domains under consideration, but that may be endlessly broadened.

The semantic frame is broadened by other properties expressing the 'rules' of the model. These rules clarify the relationships that exist between the entity and the possibility of deriving inferential deductions from the system, which can emphasise potentially incoherent representations and thus allow genuine interoperability between concepts.

Although the accuracy of the ontology description is potentially illimitable, it is necessarily bound up with the particular view of reality it aims to represent, namely its author standpoint. Thereby the model proposed by this research aims at the representation of a "hermeneutical process not static but flexible" and open to future interpretations and results [16]. Likewise, the conservation process bares on hypothesis and critical assessment and is far from entailing univocal answers.

In order to formalize historical architecture description and the whole investigation process involved in a restoration project, the proposed ontology is developed upon four principal frameworks ('domains'):

- the artefact;

- the architectural heritage investigation process;

- the artefact lifecycle;

- the actors.

The formalization of knowledge in this information structure (within those domains and their sub-domains) allows an effective representation, making it accessible, editable and manageable by all the different actors involved in the conservation process. Moreover, it makes historical contents and critical interpretations computable, which have rarely been managed before through computation [17-19]. To achieve an exhaustive description of architectural heritage, the representation has to be articulated within the four domains. The description moves generally from the building (artefact domain), and tackles issues concerning its history (artefact lifecycle), the studies that provided information to explore it (architectural heritage investigation process) and necessarily people concerned with the building for various reasons (actors). Although the model framework has been developed from scratch, several classes and properties bear upon CIDOC structure. As it will be explained in the next paragraphs, some declarations were directly reused and several taxonomies have been further developed starting from existing classes.

The proposed model provides a structure that could support a wide and specific description of historical architecture in order to enhance better preservation strategies and ensure the responsible protection and transmission of that knowledge in future (Figs. 1 and 2).

\subsection{The modelling framework for representing architectural heritage}

\subsubsection{The representation of artefacts}

The building physical features and its context are described within the artefact domain. Spatial and constructive classes together with several properties that specify the different contents have therefore been defined in this context.

Spatial classes pertain properly to the architectural perspective and are articulated into four main groups: 'spatial_complex', 'building_unit', 'spatial_unit' and 'spatial_component'. In particular, spatial qualities are mainly described by classes such as: 'spatial_complex', 'building_unit'. 'spatial_complex' relate to a group of buildings considered as a whole, such as the Santa Giulia complex in Brescia; 'building_unit' represents a building with a single identity, while function (civil, religious, etc.) and typology (house, temple, baths, etc.) are specified through different subclasses derived from the primary class.

Spatial articulation is rather expressed by 'spatial_unit' and 'spatial_component' classes through which it is possible to achieve a representation of the building's spatial structure. This is conceived as a 'whole' made of multiple 'spatial units', which are parts of the building, each with its own architectural and functional identity, but bound within a contiguous spatial zone. As examples, we may consider a roman domus whose plan consists of atrium, triclinium, tablinum, peristilium, alae, and cubicula; or a church, which may comprise a chapel and a bell tower. To further describe spatial structure, the model provides a more basic representation level: 'spatial_component', which allows description of a minimal spatial element that may not be further divided, i.e. in the case of a peristilium, the courtyard and the porch; or in a church, the nave, the apse or the transept.

According to the complexity of assembly, constructive entities are compiled in terms of 'construction_unit', 


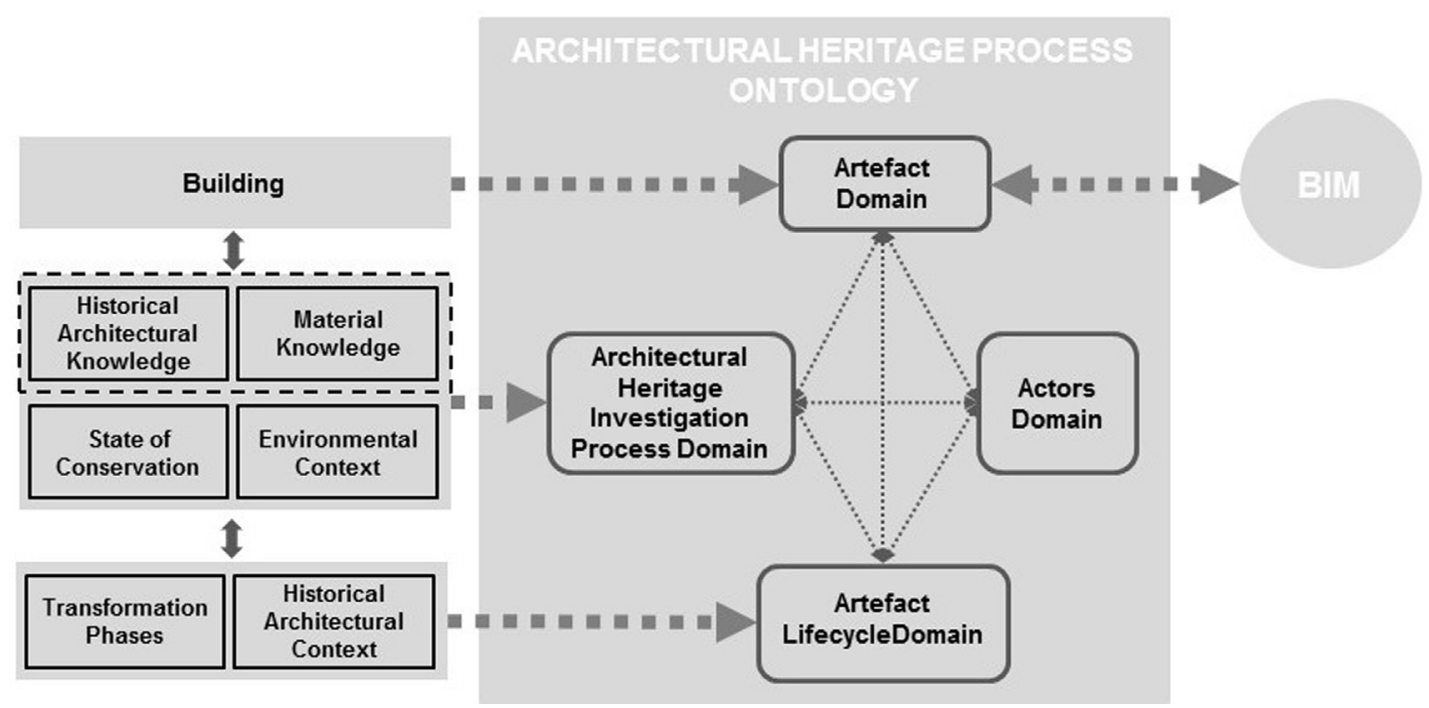

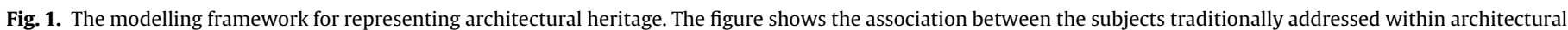
heritage studies and the ontology domains. The dashed frames bound the subjects so far modelled.

'construction_component', 'construction_element' and 'constructive_material'. 'construction_unit' refers to the most complex parts, i.e. 'covering', 'floor', 'elevation_structure' and 'foundation'.

At the lower representational level 'construction_component' represents 'communication, horizontal or elevation_component'. The first refers to all types of communication structures, either vertical - for example 'stair' - or horizontal, such as 'window' or 'door'. The horizontal elements may be structural, such as a concrete floor (class of structural horizontal component: 'floor' and class of constructive element: 'concrete') or a stone vault (class of structural horizontal component: 'vault' and of constructive element: 'stone'), or non-structural, such as fault vault (class of not-structural horizontal component and subclass: 'fault vault') or a wooden 'counter_floor'. Finally, the elevation components include 'column', 'pillar', 'wall', 'partition', etc.

The entities that comprise the 'construction_element' class are divided into 'complex' and 'simple_element'. The complex ones are compound parts, which may be 'vertical' or 'horizontal', 'decoration' or 'finishing' items. For example for vertical elements we may have 'masonry' and its components ('external' and 'internal_wall_layer', and 'nucleus'), 'pier', 'abutment'; horizontal items are 'arc' or 'lintel'; finishing may be 'plaster'
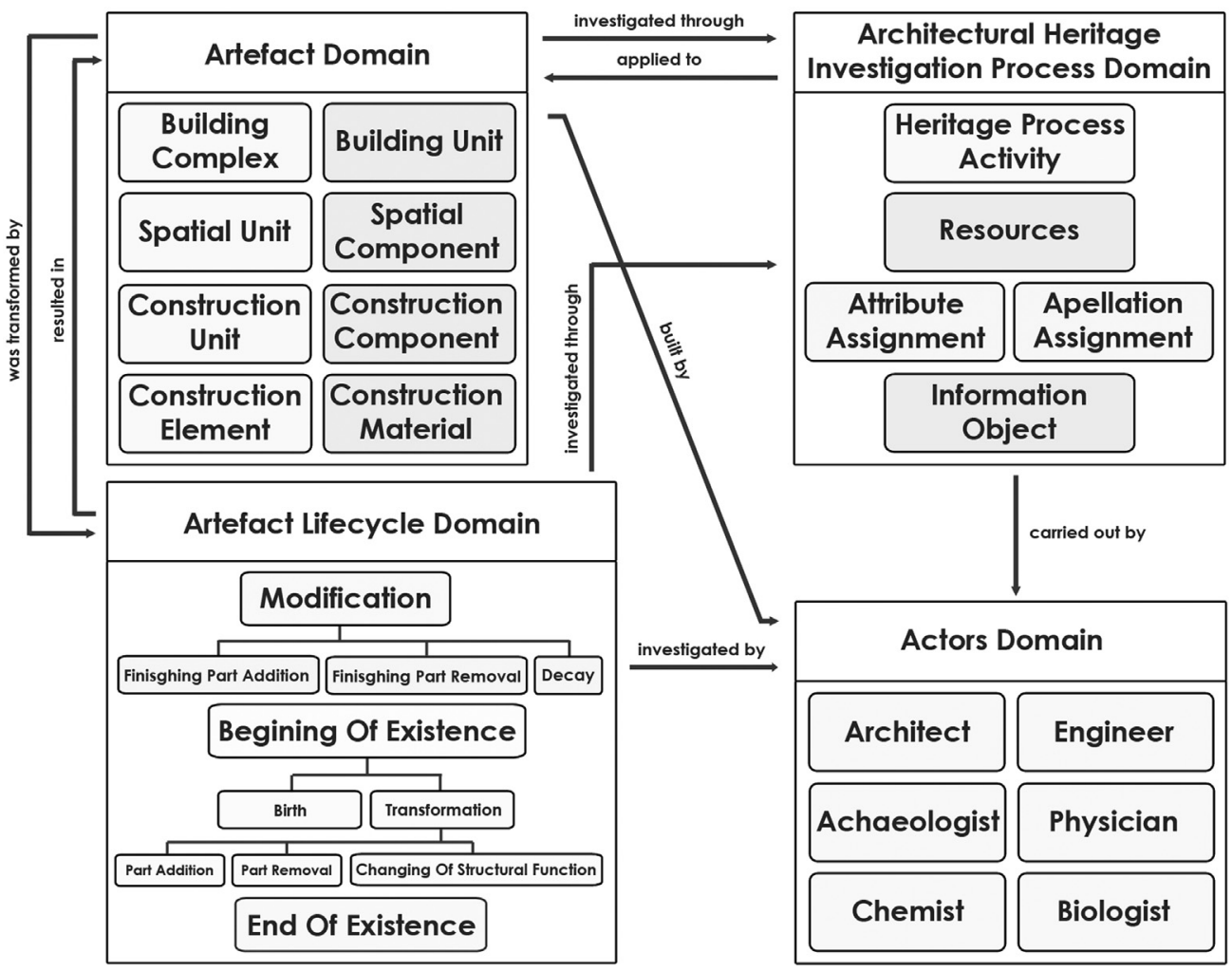

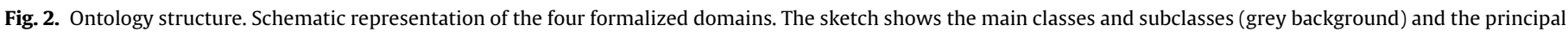
relations occurring between them (dashed arrows). 
or 'flooring'; decorations refer to 'fresco', 'mosaic', 'stucco', etc. A further class refers to 'visual_item', which concerns all those constructive elements that provide written information, such as 'inscription' or 'brick_stamp'. The 'simple_element' class refers to items that are generally the basic components of the structure, such as 'clay_element' ('brick', 'tile', etc.), 'mortar_joint', 'stone_element' ('draft', 'block', 'ashlar', 'splinter', etc.). The description of the constructive entities is then concluded with the 'construction_material' taxonomy.

Finally, the 'moveable_element' class completes the general description, gathering 'furniture' and individual elements such as 'altar', 'basin', 'statue', etc.

Complex entities, either spatial or constructive, composed of multiple lower level entities, are described by means of assembly properties: 'part_of/'whole_of'.

By way of illustration of an assembly relationship, we can say that a peristilium is a 'whole_of' a courtyard and four porches. Conversely, the spatial components may be described through the property 'part_of'. Therefore, it would be possible to affirm that its courtyard is 'part_of' a peristilium. Referring to constructive issues, a wall may be described as a 'whole_of 'masonry units', 'opening' and 'curtain wall'; conversely, an opening may be described as 'part of' the wall.

As well as assembly relationships, the description may provide information through object properties. A wall may therefore also be described by domain-specific properties - pertaining only to the instance considered - referring, for example, to its geometry (dimensions), its stratigraphy (Harris matrix), or to its dating.

Moreover, to increase knowledge about these elements, it is possible to investigate either planning items or even social issues such as patronage, specific function, and use. These issues may be adequately described through properties such as 'is commissioned by'; 'has function'; 'is studied by' that refer to other domains (actors, lifecycle, investigation process).

The artefact domain actually provides the description of the historical building physical configuration and supports the completion of the representation through the properties dealing with other frameworks.

Classes and properties of artefact domain were modelled from scratch, although they were integrated with already existing CIDOC classes as 'persistent item', 'man made thing' which certainly pertain to the domain considered.

The articulation of the model of the artefact in terms of spatial and constructive components is also influenced by the BIM common representation template; in fact, the use of BIM representation template allows to declare and define the different constructive components of the artefact and their attributes at a scale that is relevant for the architectural organism representation and, above all, according to the building constructing logic ("as built"). Namely, this issue particularly concerns historical artefacts comprehension. Often ancient buildings present very particular constructive solutions that have to be understood in their singular dimension but also, necessarily, put into relation to all the other components, according to the building architectural logic. To make an example we may consider the ancient base of a column reused as a stone for a wall. Within a restoration project it is certainly important to read its specific identity but, in the meanwhile its new structural function brought to existence by the construction of the wall, should not be overlooked. This latter aspect is ensured by BIM template, while the first one needs a different representation instrument. Hence, the proposed model for the artefact takes into account the original BIM schema but then relies on the use of semantic networks (developed through information ontologies) to reach the description level required by historical architecture not reachable through the simple BIM template.

\subsubsection{Representation of the architectural heritage investigation} process: activities, actors, and resources

The domain 'heritage_investigation_process_activity' represents all the studies required for the conservation process of a piece of historical architecture. These studies may differ in nature, either directly performed on the building or derived away from it. According to these specifics, the model provides two subclasses: one for 'direct_analysis_activity' which includes activities such as 'survey', 'masonry_analysis', and 'diagnostic_analysis'; and the other for 'indirect_analysis_activity', which allows the description of activities such as 'bibliographical' and 'archival_investigation', 'plant' and 'metrology_analysis', 'masonry_investigation', etc. As well as the classes, the model facilitates the representation of a single investigation with a general template, which has been conceived to fit the specificity of each analysis (Fig. 3). Besides their definition, each activity is described through the resources employed to develop it, and how it is able to be assigned. The model thus presents several classes that refer to resources, such as 'actor', 'tool', 'method', 'external_reference', and to 'assignments'.

The 'actor' class represents all the specialists involved in the activity ('architect', 'engineer', 'physician', 'chemist', 'biologist', 'archaeologist'), the 'tool' class includes all the means employed during the activities ('camera', 'microscope', etc.) and 'method' is used to describe the kind of analysis developed ('measurement', 'comparing', 'statistical_analysis', etc.). Finally, the 'reference_information_object' class refers to all the theoretical concepts needed within the analysis (i.e. ancient measuring units), or assignments resulting from other investigations.

The results achieved from the analysis may differ widely in nature, and therefore to represent these individualities and to suit the issues of the conservation process, specific classes have also been conceived [4]. Analytical data, for example, the results of the microscopic investigation, are included in the class 'information_object'. Conversely, all information derived from an interpretation activity is gathered into the 'assignment' class. When the result of an interpretation contributes to the definition of an identity item, it pertains to the appellation assignment class. As an example, this may derive from an architectural typology, or a particular owner (e.g. 'livia's house'). Otherwise, the 'attribute assignment' class would represent the result if it concerns a wider concept that may refer to dating, cultural matrix, object origin, or paternity.

The proposed framework merges 'new' classes with CIDOC declarations. The classes pertaining to the investigation process contents related to analysis typologies and methods are newly designed, while information and interpretation contents are represented through CIDOC language.

The property that completes the representation of investigation activities, and relates the activities to the results obtained is 'provides_information_for' (Table 1).

The model for the entire investigation process that focuses on architectural comprehension for conservation begins with the object (the 'artefact') since every building will require its own particular investigation. The property that describes the relation between the fabric and the analysis is 'applied_to'.

As mentioned above, the expressive and descriptive potential of the proposed model does not reside only in the formalization of the semantic network but also in the ability to infer facts that are not explicitly expressed in the ontology. The inference engine, integrated with the ontology-based system, is able to verify the formalized knowledge ensuring the consistency and coherence of the information represented in the model. By operating on the instances of the ontology, such rules can intervene in the case of relationships, constraints, and specifications associated with the entity to which they belong to. Those rules, formalized with the 


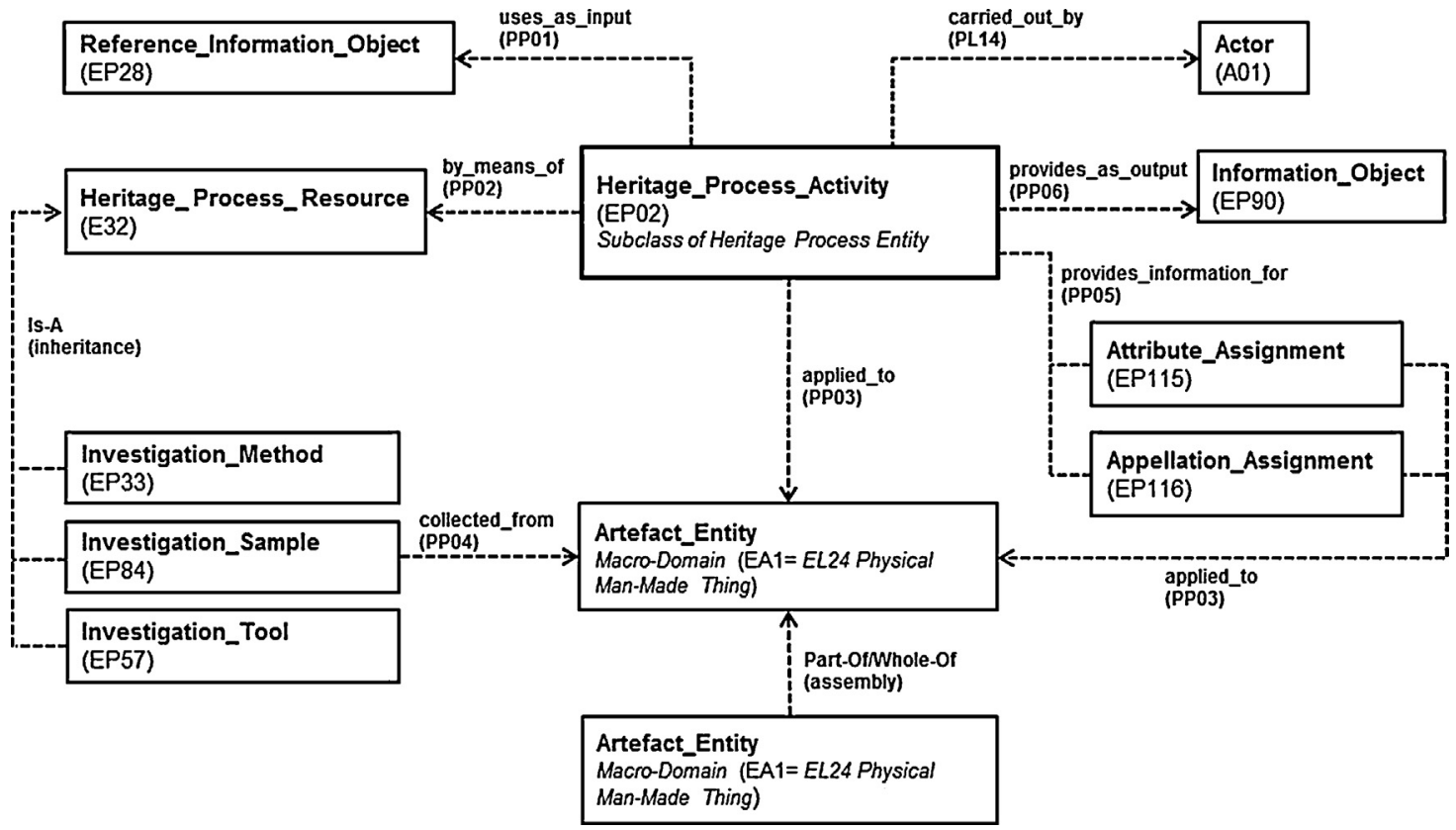

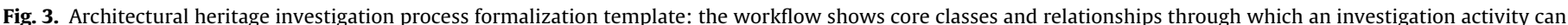

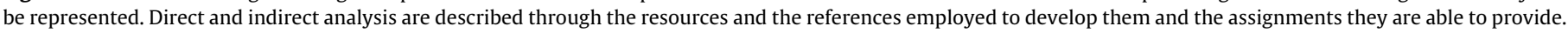

semantic web rule language (SWRL), are based on the predicate logic in which each proposition requires an implication between an antecedent (body) and a consequent (head). To further verify the results emerging from the investigation process, appropriate

Table 1

Masonry type investigation activity representation. The activity description is developed within the ontology through different properties illustrated above.

\begin{tabular}{|c|c|c|c|}
\hline Cod. & \multicolumn{3}{|c|}{ Name: Masonry type Investigation Activity (MTI_ma/ln) } \\
\hline Class & $\operatorname{cod}$ & \multicolumn{2}{|c|}{ Masonry type investigation activity } \\
\hline Subclass of & & \multicolumn{2}{|c|}{ Masonry investigation activity } \\
\hline Superclass of & & \multicolumn{2}{|l|}{ - } \\
\hline \multirow[t]{25}{*}{ Object properties } & & \multirow[t]{2}{*}{ Uses as input } & $\begin{array}{l}\text { Survey document [EL 26]: } \\
\text { geometrical survey }\end{array}$ \\
\hline & & & $\begin{array}{l}\text { Reference information } \\
\text { object: masonry type }\end{array}$ \\
\hline & & \multirow[t]{3}{*}{ By means of } & Tool [EL21]: camera \\
\hline & & & Tool [EL21]: pocket tape rule \\
\hline & & & Tool [EL21]: drawing tablet \\
\hline & & \multirow[t]{6}{*}{ By means of } & $\begin{array}{l}\text { Method [EP 22]: visual } \\
\text { analysis }\end{array}$ \\
\hline & & & Method [EP 22]: measuring \\
\hline & & & Method [EP 22]: \\
\hline & & & identification \\
\hline & & & $\begin{array}{l}\text { Method [EP 22]: laboratory } \\
\text { analysis }\end{array}$ \\
\hline & & & $\begin{array}{l}\text { Method [EP 22]: masonry } \\
\text { distribution representation }\end{array}$ \\
\hline & & \multirow[t]{4}{*}{ By means of } & Sample [EP23]: sMN1 \\
\hline & & & Sample [EP23]: sMN2 \\
\hline & & & Sample [EP23]: sMN3 \\
\hline & & & Sample [EP23]: sMN4 \\
\hline & & \multirow[t]{2}{*}{ Applied to } & $\begin{array}{l}\text { Elevation component } \\
\text { [EA122] }\end{array}$ \\
\hline & & & Wall: ma/ln \\
\hline & & \multirow[t]{6}{*}{ Provides as output } & Information data: \\
\hline & & & Masonry type data sheet \\
\hline & & & M1 \\
\hline & & & M2 \\
\hline & & & M3 \\
\hline & & & M4 \\
\hline & & Provides & Attribute assignment? \\
\hline & & information for & Dating \\
\hline \multirow[t]{2}{*}{ Data properties } & & Developed on & September 2014 \\
\hline & & Developed by & Silvia Cutarelli \\
\hline Note & & & \\
\hline
\end{tabular}

rules of reasoning have been introduced into the proposed model to compare assignments resulting from different analysis.

The one shown below is a rule able to verify any inconsistencies between the dating assigned to the identified masonries belonging to a wall, and the topological relationships that exist between them, represented by the Harris matrix. In this way, it is possible to compare the laying sequence and thus the topological relationships that exist between the wall units with the dating that come from other investigation activities.

'Wall_Unit' $(? \mathrm{a} 0) \wedge$ 'Wall_Unit' (?a1) $\wedge$ 'WallUnitInterpretedAge' (?a0,?age1) ^ 'WallUnitInterpretedAge' (?a1,?age2) $\wedge$ 'cover' (?a0,?a1) ^ 'swrlb:greaterThanOrEqual' (?age2,?age1) $\rightarrow$ 'temporal_relationship_incoherence' (?a1, true) $\wedge$ 'temporal_relationship_incoherence' (?a0, true).

More specifically, in this rule we declare that if there are two different individuals that belong to the Wall Unit class (instances?a0 and?a1) with $(\wedge)$ an Interpreted Agedata-type property associated (?age1-WallUnitInterpretedAge of?a0 instance and?age2-WallUnitInterpretedAge of?a1 instance), and $(\wedge)$ if between those Wall Unit individuals (?a0 and?a1) exists the cover relationship (?a0 cover?a1), and $(\wedge)$ if the Wall Unit covered by the other one has an earlier dating (?age2datatype property of?a1 instance isgreaterThanOrEqual of?age1 datatype property of?a0 instance), then $(\rightarrow)$ there is an inconsistency between the two different types of information (the temporal_relationship_incoherence data properties of the?a1 and?a0 instances become true). This example shows how it is possible to point out eventual interpretative incoherence through simple logical deductions.

\subsubsection{Representation of artefact lifecycle}

The reconstruction of the lifecycle of historical architecture represents the synthesis of historical investigation with the core of critical appraisal in the conservation process. The knowledge provided in the analysis phase leads to deep comprehension, making it possible to identify building transformations. Determining the constructive phases in the building's fabric, as well as focusing on its architectural specificities, also means focusing attention on the contexts that produced them and, consequently, on the cultural 


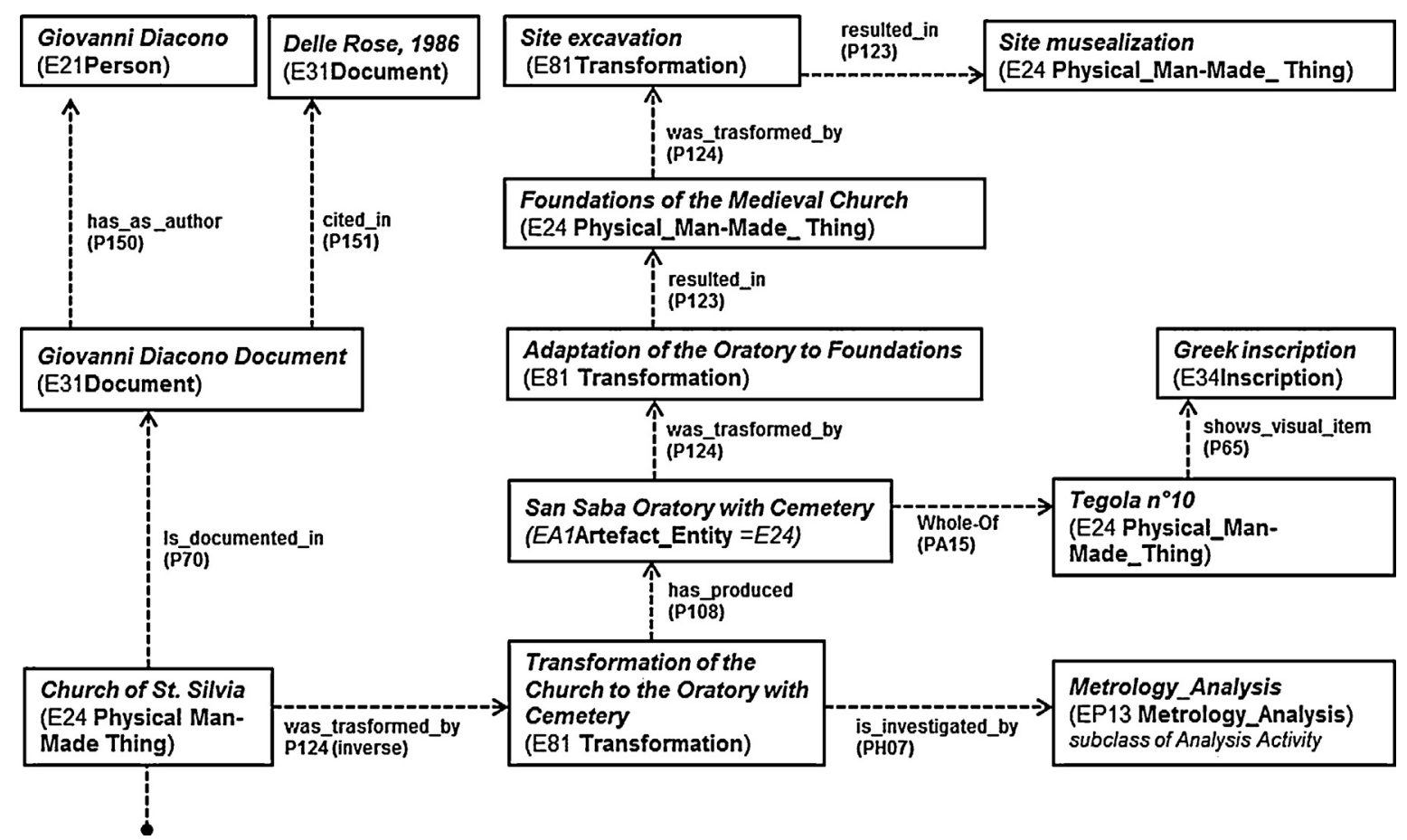

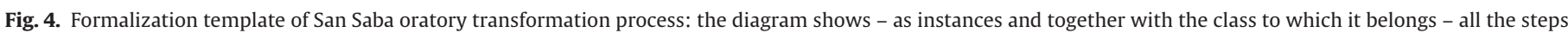

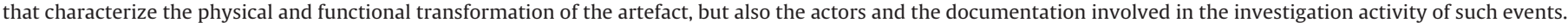

stratification responsible for the development of the building's identity. Only profound comprehension of the material and cultural aspects of its historical architecture identity can properly address the design of the conservation, by highlighting critical issues, constraints, and values.

The lifecycle domain gathers all the activities that have, in many different ways, involved the transformations of the building or influenced architectural configuration, use, or even identity itself; therefore all the other domains developed in the ontology must be involved.

The property 'results_from' expresses the relationship between the lifecycle domain - the building's transformation/s - and the artefact domain - the architectural organism, or parts of it. It describes which activity/ies may have occurred during the building construction or its transformation.

CIDOC classes define the principal identified activities: 'bringing_to_existence', 'transformation' and 'modification'. 'bringing_to_existence' refers to the fundamental realization of the building or part of it. 'Transformation' refers to intermediate stages of construction that may have completely or partially changed the building's identity. Finally, 'modification' refers to activities that have not concerned the architectural identity, like removed coatings or added partitions.

Generally, the events concerned are documented or deduced from former and current studies. Thus they necessarily relate to the 'heritage_investigation_process_activity' domain. Properties that connect both the domains are: 'is_documented_by' and 'is_investigated_by'. The first refers to a scientific publication or to a direct source, as archival documents or epigraphs, the second to a critical interpretation, which usually arises from investigation activity (Fig. 4). In conclusion, the proposed model is able to properly represent the complex processes that lead to the creation of a historical building by describing either its physical attributes or the studies that have contributed to its identification.

\subsection{The application case}

The model was successfully tested in the investigation process developed within the conservation of the 6th-century San Saba oratory in Rome (Figs. 5 and 6). The description of the building architecture and construction features were represented mainly by the artefact domain as is shown in Table 2.

The oratory is the result of several transformations occurred through the centuries. In the 6th century, a roman house aula was adapted into an oratory managed by a small community of monks. Inside the building, a cemetery gradually built through the years was included. Also, wall paintings were added and some remains of the frescos are still visible. In the late 11th century the oratory was buried as it was used as a foundation of the upper church. Only in the early XXth century, during an important campaign of restoration works, the oratory was brought to light and made accessible.

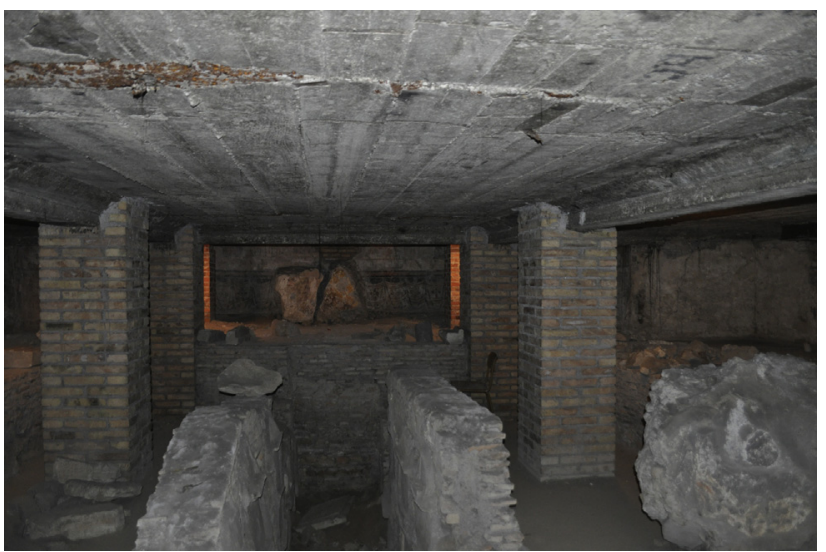

Fig. 5. San Saba Oratory. General view of the building towards the apse. 


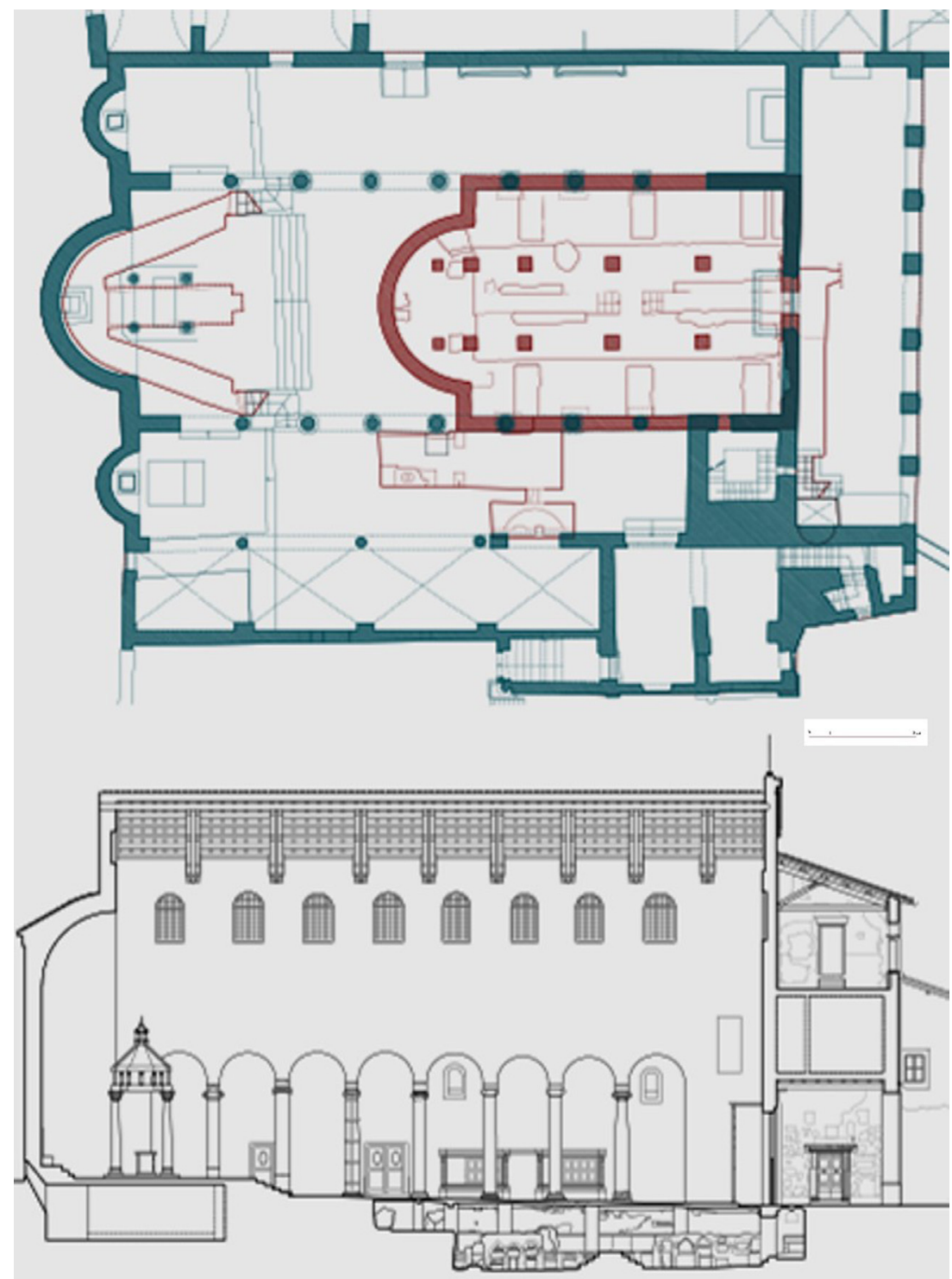

Fig. 6. San Saba Oratory. Building plan and longitudinal section (drawings by Silvia Cutarelli).

The investigation process, developed to support the restoration and management design, aimed both at the deepening of the historical knowledge and at the documentation of its state of conservation. The activities were carried out by several specialists (architects, engineers, scientists from the ISCR _MIbact) and the results provided were formalized in a common framework able to manage either their specificity or the possibility of integrating the different outputs. A schematic representation of the ontology structure describing the building transformation, and the investigations carried out for its comprehension are shown on Fig. 4.

\section{Building information modelling for knowledge-enriched visualization of heritage artefacts}

Although a large amount of heritage documentation cannot be directly represented through drawings, heritage activities still produce and require a large amount of graphical representation. For this reason, we decided to integrate the ontological knowledge base with a modelling environment based on the BIM methodology. The choice of a BIM approach over other digital representations (such as CAD or GIS) was based on two main factors:
- the possibility to virtually build the artefact as a set of spatial and physical components, similar to the ones depicted in the ontology-based model;

- the possibility to associate information and semantics to each component in order to represent non-geometrical aspects such as materials, dating, or construction features.

More specifically, we implemented a direct correspondence between the representation of the 'Artefact' domain in the knowledge base, and the entities and properties in the BIM environment, allowing an effective exchange of information between the two systems without data loss. This connection enriches the 3D representation of the artefact, adding to it all the information that has been stored, formalized and verified in the knowledge base, making it available to all the stakeholders and operators of the different heritage process activities. At the same time, they are able to interrogate and edit the 3D model, adding to and modifying it without altering the knowledge base. By means of this system, a single model can integrate the geometrical and semantic features of the artefact, thus improving the coherence and consistency of the representation. 


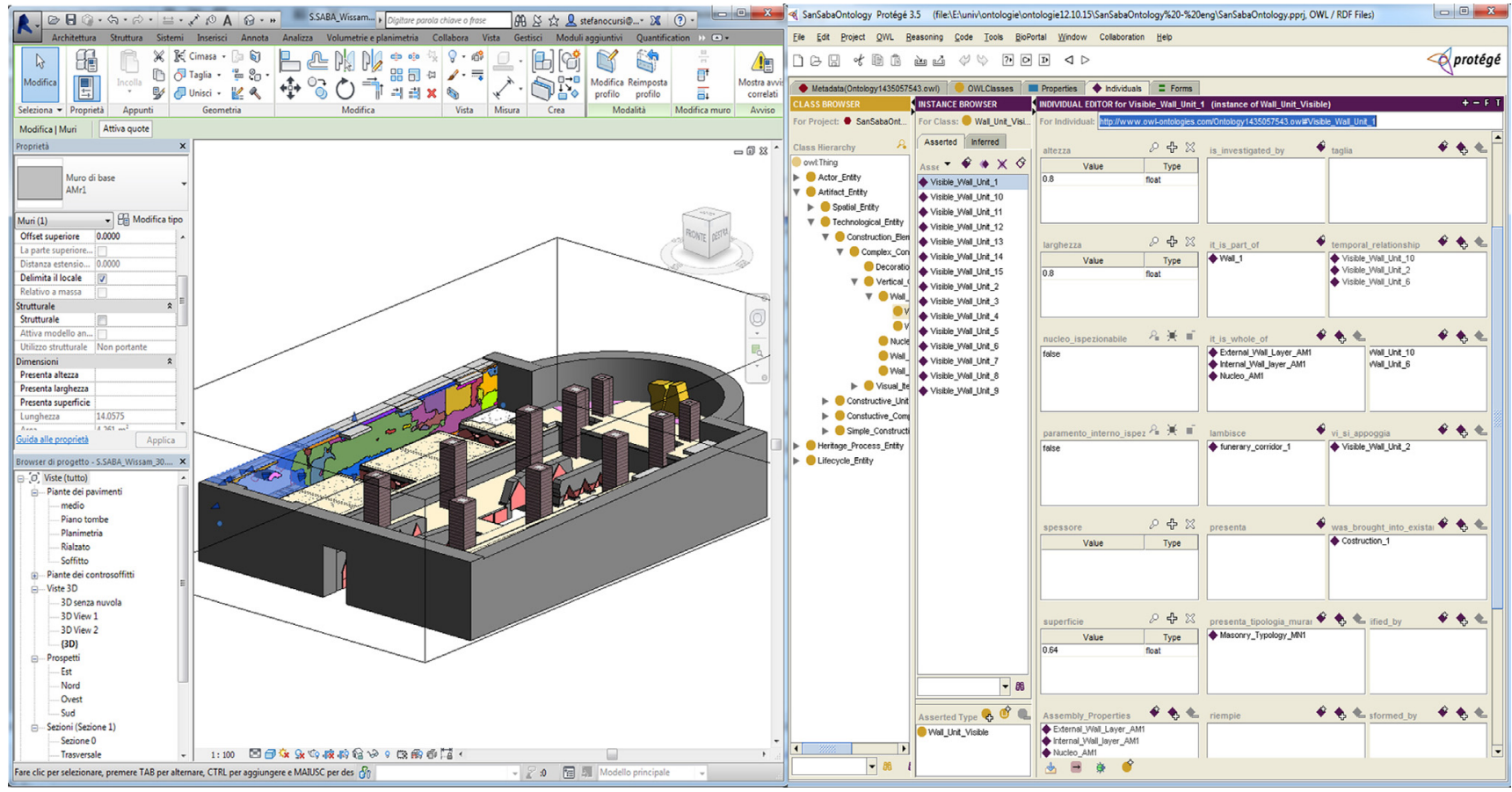

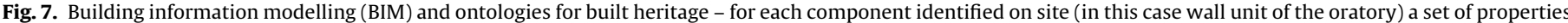

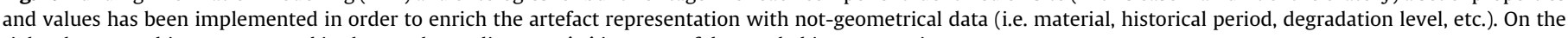
right, the same object represented in the ontology editor protégé in terms of data and object properties.

Table 2

San Saba Oratory representation. The spatial unit is described through object properties and data properties that are formalized within the ontology.

\begin{tabular}{|c|c|c|c|}
\hline \multirow{3}{*}{$\begin{array}{l}\text { Cod. } \\
\text { Classe } \\
\text { Object } \\
\text { properties }\end{array}$} & \multicolumn{3}{|c|}{ Name: San Saba Oratory } \\
\hline & \multirow{9}{*}{$\begin{array}{l}\text { cod } \\
{[\text { P131] }}\end{array}$} & \multicolumn{2}{|c|}{ Spatial unity: oratory [EA36] } \\
\hline & & \multirow[t]{8}{*}{ It is whole of } & Spatial components \\
\hline & & & Aula [EA45a] \\
\hline & & & Apse [EA46] \\
\hline & & & Funeral aisle [56] \\
\hline & & & Grave [EA57] \\
\hline & & & Aggregate of graves \\
\hline & & & Niche burial [EA59] \\
\hline & & & Isolated grave [EA62] \\
\hline & \multirow[t]{2}{*}{ [P132] } & \multirow[t]{2}{*}{ It is part of } & $\begin{array}{l}\text { Worship building } \\
\text { [EA10] }\end{array}$ \\
\hline & & & $\begin{array}{l}\text { San Saba Church } \\
\text { [EA101] }\end{array}$ \\
\hline & \multirow[t]{4}{*}{ [P9] } & \multirow[t]{4}{*}{ It is investigated by } & Actors [EAC1] \\
\hline & & & Krautheimer [EAC5] \\
\hline & & & Delle Rose [EAC13] \\
\hline & & & Fiocchi Nicolai [EAC6] \\
\hline & \multirow[t]{6}{*}{ [P123] } & \multirow[t]{2}{*}{ Results from } & Activity [E7] \\
\hline & & & Transformation [EL81] \\
\hline \multirow[t]{4}{*}{ Data properties } & & Area measurement & $155 \mathrm{~m}^{2}$ \\
\hline & & It is hypogean & Boolean: yes \\
\hline & & It is accessible & Boolean: yes \\
\hline & & It is visitable & Boolean: no \\
\hline Note & & \multicolumn{2}{|c|}{$\begin{array}{l}\text { Generally the oratory typology is referred to an } \\
\text { isolated building, therefore it should be } \\
\text { considered as a building unit [EA3]; although } \\
\text { in the present case the building has been } \\
\text { reused after its foundation, in the medieval } \\
\text { period, and today may not be considered as a } \\
\text { unique unit but as part of a bigger structure } \\
\text { (spatial unit [EA36]) }\end{array}$} \\
\hline
\end{tabular}

In order to apply the model to the case study, we chose BIM-based software Revit (http://www.autodesk.com [20]), while a connection with the Protégé (http://protege.stanford.edu [21]) environment was ensured through the development of an ad-hoc software prototype, able to connect the two relational databases linked with each environment (Fig. 7).

\section{Conclusions}

This paper presents an information model aimed at supporting the representation and management of knowledge for the architectural heritage conservation processes. The proposed model has at its core an ontology-based representation of the artefact and of the knowledge collected, used and shared by the different actors during investigation and conservation activities, fully adaptable to their discipline-specificity and to the uniqueness of the artefact. While at present ontologies have been only used to model information and knowledge regarding very narrow disciplines and aspects of cultural heritage, this research presents a wider model that focuses on the entire domain of architectural heritage and its conservation process. In particular, although many CIDOC declarations have been integrated into the model, these are actually related to a new framework that matches the logic structure of the conservation process, so that a conservation professional may easily manage with it. The use of ontologies, as well as their integration with a building information modelling environment, allows a homogeneous, accessible and computable structured formalization of both the direct and indirect knowledge necessary for the full comprehension of an architectural artefact.

Although conceived to support the entire conservation process, the proposed knowledge-based model has been specifically oriented around the investigation process. Nevertheless, we can already fully appreciate the impact that such a model may have on the architectural heritage field, either for scientific or professional purposes. In addition, the proposed model, focusing on the entire design process, may be configured to act as a supporting guide for information and knowledge management in conservation practice, particularly within public institutions. 
From this perspective, the research presented here opens up new possibilities for further investigation into the use of ontologies to support the conservation process and, in particular, the preliminary planning and conservation design phases. Furthermore, the introduction of information systems for architectural heritage allows each artefact be associated with a coherent, comprehensive and up-to-date knowledge base that could contribute towards the enhanced planning of historical building maintenance, an overriding topic within the current conservation debate.

\section{Acknowledgments}

The work has been developed within the Research Project of National Interest directed by Stefano Della Torre 'Built heritage information modelling and management (BHIMM). A model for architectural restoration based on knowledge' and was performed by the research unit conducted by Donatella Fiorani combining the competences of conservation architects with those of the engineering group coordinated by Gianfranco Carrara and Antonio Fioravanti.

\section{References}

[1] T. Gruber, A translation approach to portable ontology specifications, Knowledge Acquisition 5 (2) (1993) 199-220.

[2] N. Guarino, P. Giaretta, Ontologies and knowledge bases, towards a terminological clarification, in: N. Mars (Ed.), Towards Very Large Knowledge Bases: Knowledge Building and Knowledge Sharing, IOS Press, Amsterdam, 1995, pp. 25-32.

[3] D. Fiorani, Materiale/Immateriale. Frontiere del restauro, Mater. Strut. Prob. Conserv 5-6 (2014) 9-23.

[4] S. Settis, L'illusione dei beni digitali, Boll. ICR 5 (2002) 18-20.

[5] F. Cantone, Shared technologies in archeologia. Nuove prospettive di gestione e condivisione di dati in rete, in: Archeologia e Calcolatori, Paola Moscati (Ed.), Firenze, 2005, pp. 271-290 (16)

[6] N. Crofts, M. Doerr, T. Gill, S. Stead, M. Stiff, Definition of the CIDOC Conceptual Reference Model, ICOM/CIDOC Documentation Standards Group e CIDOC CRM Special Interest Group, 2010 http://www.cidoc-crm.org/docs/ cidoc_crm_version_5.0.2.pdf.

[7] R. Cacciotti, M. Blasko, J. Valach, A diagnostic ontological model for damages to historical constructions, J. Cult. Herit. 16 (1) (2015) 40-48.
[8] M. Agathos, S. Kapidakis, A meta-model agreement for architectural heritage, metadata and semantics research, Commun. Comput. Inf. Sci. 390 (2013) 384-395.

[9] S. Mecca, M. Masera, C. Cirinnà, Knowledge management approach for conservation of Earthen Architecture, in: Conference Proceedings of Joint CIB W65/W55/W86 Symposium, Rome, 2006.

[10] S. Fai, K. Graham, T. Duckworth, N. Wood, R. Attar, Building information modelling and heritage documentation, in: Conference Proceedings of XXIII CIPA International Symposium, Prague, 2011, p. 8.

[11] S. Garagnani, A.M. Manferdini, Parametric accuracy - Building Information Modelling process applied to the cultural heritage preservation, in: 3DArch2013, Conference Proceedings of The International Archives of the Photogrammetry, Remote Sensing and Spatial Information Sciences, Trento, 2013, pp. 87-92.

[12] C. Dore, M. Murphy, Integration of historic building information modelling (HBIM) and 3D GIS for recording and managing cultural heritage sites. In Virtual Systems in the Information Society, in: Proceedings of the 18th International Conference on Virtual Systems and Multimedia (VSMM), Milan, Italy, 2012, pp. 369-376.

[13] P. Pauwels, R. Bod, D. Di Mascio, R. De Meyer, Integrating building information modelling and semantic web technologies for the management of built heritage information, in: 1st International Congress on Digital Heritage, Marseille, France, 2013

[14] D. Simeone, S. Cursi, I. Toldo, G. Carrara, B(H)IM - Built Heritage Information Modelling - Extending BIM approach to historical and archaeological heritage representation, in: Fusion, E. Thompson (ed.), in: Proceedings of the 32nd eCAADe Conference (Vol. 1), Newcastle upon Tyne, England, UK, 2014, pp. 613-622.

[15] D. Calvanese, G. De Giacomo, M. Lenzerini, D. Nardi, R. Rosati, Description logic framework for information integration, in: Proc. of the 6th Int. Conf. on the Principles of Knowledge Representation and Reasoning (KR'98), 1998, pp. 2-13.

[16] F.T. Fonseca, J.E. Martin, Toward an alternative notion of information systems ontologies: information engineering as a hermeneutic enterprise, J. Am. Soc. Inf. Sci. Technol. 56 (1) (2005) 46-57.

[17] M. Doerr, Ontologies for cultural heritage, in: S. Staab, R. Studer (Eds.), Handbook on Ontologies, Springer, Berlin Heidelberg, 2009, pp. 463-486.

[18] E. Costamagna, A. Spanò, Semantic Models for Architectural Heritage Documentation. In: Progress in Cultural Heritage Preservation, Lecture Notes in Computer Science, Vol. 7616, Springer-Verlag Berlin Heidelberg, Berlino, 2012, pp. 241-250.

[19] K. May, C. Binding, D. Tudhope, A STAR is born: some emerging semantic technologies for archaeological resources, in: E. Jerem, F. Redő, V. Szeverényi (Eds.), On the Road to Reconstructing the Past. Computer Applications and Quantitative Methods in Archaeology (CAA), Proceedings of the 36th International Conference, Archeaeolingua, Budapest, 2008, pp. 111-116.

[20] http://www.autodesk.com.

[21] http://protege.stanford.edu. 